\title{
Exploring The Use Of Leading Management Practices In Enterprises
}

\author{
Sonja Treven, Ph.D., University of Maribor, Slovenia
}

\begin{abstract}
Numerous management practices have emerged in recent years in response to competitive pressures calling for improved enterprises' working and behavior. Despite the relevance of this phenomenon there are limited research evidences about comprehensive comparison of several and contently different management practices as carriers of corresponding management ideas behind them. In this study we examine the frequencies, patterns, and key drivers of 25 most used management tools by managers and professionals in enterprises, as selected appearance form of management practices in enterprises. The results indicate that tools are used by managers significantly more frequently than by professionals, indicating significant differences in patterns of tool usage when comparing the two groups. Among the key drivers of tools' use by managers, education dominantly influence on tools use, work experiences had only a minor impact, while organizational size does not significantly influence on tools use. For professionals only enterprise size significantly influences on usage of two tools, while the impact of education and working year on tools usage is not significant. The findings offers disseminate knowledge for improving enterprises working through use of management tools and strengthen the theoretical base necessary for future selection and utilization of tools in enterprises production management.
\end{abstract}

Keywords: Employees; Driver; Enterprise; Frequency; Management Practice; Pattern, Tool

\section{INTRODUCTION}

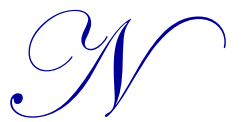

umerous management practices have emerged in recent years in response to competitive pressures calling for improved of enterprises' working and behavior (Morgan and Wang 2010; CameloOrdaz et al. 2012; Choudhary et al. 2013). The central part of enterprises modeling presents selection and utilization of policies and strategies through selection and application of different management practices as carriers of corresponding management ideas (Armstrong 2006; Ralston et al., 2011). Thus, enterprises constantly re-think about the adequacy of chosen practices and possibilities for utilization of new practices (Kumar et al., 2011; Jarzabkowski et al. 2013).

The comparison of different management ideas in enterprises are linked with plenty of unsolved issues (Rigby 2001; Morgan and Wang 2010; Vaccaro et al., 2012; Choudhary et al. 2013). Each idea can also exists in different appearance forms ranging from concept, methodologies, methods, techniques, instruments to tools, which are differently developed and defined. In management researchers are primarily oriented on consideration of management tools, as most recognizable and frequently appearance form of management practices and ideas behind them (Thun, 2010; Dabic et al., 2013). We followed previous studies with development of methodological and content consideration of management tools' frequency, patterns and drivers.

In literature authors emphasize importance of simultaneously use of different management tools, but only individual studies reported about research of several contently different management tools (O'Hare et al. 2010; Potocan et al., 2012; Choudhary et al. 2013). Additionally, empirical studies reported contradictory results about the directions and the strength of correlations between personal, organization, and environmental drivers and management tools usage (Zheng et al. 2010; Vaccaro et al. 2012), and about tools' usage among diversified groups of employees in enterprises (Lee et al. 2011; Choudhary et al. 2013). 
This article addresses controversies in considering management tool use by providing comprehensive research and empirical study. From theoretical viewpoint this study contributes to the existing literature with broader consideration of frequency and patterns for more and contently different management tools, simultaneous influences of key drivers on each considered management tool and differences of tools' usage between managers and other employees. An empirical part of article examines international comparison of 25 most frequently used management tools, frequency and patterns for the 25 most used management tools among managers and professionals, and simultaneous influences of key drivers on each of top ten most used tools among managers and professionals in Slovenian enterprises.

\section{LITERATURE REVIEW AND HYPOTHESES}

Enterprises for selection and utilization of management practices use management tools and define them as detailed procedures or processes with a specific purpose in business (Rigby and Bilodeau 2009; Thun 2010; Potocan et al. 2012). Recent studies have emphasized the importance of examining individual management tools and comparison of individual management tools (Morgan and Wang 2010; O'Hare et al. 2010; Kumar et al. 2011).

The studies about usage of majority of management tools are still limited. Often mentioned is Bain Research Group's international study about the usage and satisfaction with 25 most used management tools. Bain's study has been going on since 1993 and covered 60 countries (Rigby 2001; Rigby and Bilodeau 2009, 2011).

Potocan and Nedelko (Potocan et al. 2012) researched inquiry knowing, characteristics, drivers, and satisfaction with 40 selected management tools. Potocan and Nedelko's study, has been going on since 2005 and, by 2012, covered 12 countries from Central and Eastern European countries and it is aimed on tools' usage in enterprises and among different groups of enterprises' stakeholders.

Table 1 summarizes findings from both streams of studies - namely, Bain's (Rigby 2011) and Potocan and Nedelko's (Potocan et al. 2012) studies - and shows the extent of the usage for the ten most used management tools in enterprises in considered areas.

Table 1. Ten Most Used Management Tools In An International Environmental

\begin{tabular}{|c|c|c|c|c|c|c|}
\hline \multirow{2}{*}{ Management Tools } & \multicolumn{6}{|c|}{ Selected International Areas } \\
\hline & $\mathbf{G L}$ & NA & $\mathbf{E U}$ & $\mathbf{A P}$ & $\mathbf{L A}$ & SLO \\
\hline 1. Benchmarking (BEN) & 1 & 3 & 1 & 4 & 3 & 2 \\
\hline 2. Strategic Planning (SP) & 2 & 2 & 3 & 2 & $1(\mathrm{t})$ & 8 \\
\hline 3. Mission and Vision Statements (MVS) & 3 & 4 & $5(\mathrm{t})$ & 3 & $1(\mathrm{t})$ & $6(t)$ \\
\hline 4. Customer Relationship Management (CRM) & 4 & 1 & 2 & 1 & 6 & $6(t)$ \\
\hline 5. Outsourcing (OUT) & 5 & 6 & $5(\mathrm{t})$ & 5 & 4 & 1 \\
\hline 6. Balanced Scorecard (BSC) & 6 & $12(t)$ & $8(\mathrm{t})$ & $10(t)$ & 5 & 9 \\
\hline 7. Core Competencies (CC) & $7(\mathrm{t})$ & 5 & $8(\mathrm{t})$ & 6 & $10(t)$ & 3 \\
\hline 8. Change management $(\mathrm{CM})$ & $7(t)$ & 9 & 4 & $8(\mathrm{t})$ & 9 & 10 \\
\hline 9. Strategic Alliances (SA) & 9 & 7 & 7 & $8(\mathrm{t})$ & 8 & 17 \\
\hline 10. Customer Segmentation (CS) & 10 & $15(\mathrm{t})$ & 12 & $10(\mathrm{t})$ & 7 & 11 \\
\hline Social media programs $(S M P)$ & 19 & 8 & $17(t)$ & 22 & 21 & 16 \\
\hline Total quality management $(T Q M)$ & 12 & 10 & 15 & 12 & $12(t)$ & 5 \\
\hline Supply chain management(SCM) & 11 & $15(t)$ & $8(t)$ & 14 & $12(t)$ & 15 \\
\hline Knowledge management $(K M)$ & 12 & 17 & 11 & 7 & 15 & 4 \\
\hline
\end{tabular}

a Note: Data for Global average (GL) 2010, North America (NA) 2010, European Union 15 (EU) (2010), Asia Pacific (AP) (2010), and Latin America (LA) (2010) are calculated based on results from management tools research conducted by Rigby and Bilodeau (2011). Ranks for Slovenia are adopted from Potocan et al. (2012). (t) stands for tight result.

Table 1 highlights the differences in the use of enterprises' management tools in selected international areas. Recognized differences we can partly explain with the results of previous studies about influence of macroeconomics conditions and level of countries development on usage of management tools (Rigby 2001; O'Hare et al. 2010; Potocan et al., 2012; Potocan et al., 2013). A more comprehensive international comparison is still relatively limited due to the complexity of different working circumstances. We focused our work in study of management tools' usage among employees in considered Slovenian organizations. 
Studies of management tool usage also offer limited evidences about possibilities and results of comparison - i.e. frequency and patterns for majority of management tools (O'Hare et al. 2010; Regazzoni et al., 2011). In spite of that several management authors have emphasized the need for development of research for determination of correlations between majority of management tools, and tools drivers which determine usage of tools in enterprises (Morgan and Wang 2010; Potocan et al. 2012; Jarzabkowski et al. 2013).

Contemporary studies of tools are based on a conceptual framework that integrates and extends prior discussions about the use of tools. For example, Kannan and Tan (2005) used empirical research to demonstrate the strength of the correlates among just-in-time, supply chain, and quality management.

We continue previous studies with research of 25 most used tools usage among professionals and managers in Slovenia enterprises. Consideration of different groups of employees is in line with research trends in theoretical and empirical management studies (Ralston et al. 2011; Lee et al. 2011; Ralston et al., 2014). The above mentioned theoretical and research findings about the use of management tools between employee groups suggest the following hypotheses:

H 1: Managers use management tools more often than professionals.

H 2: Significant differences exist in the pattern of management tool use between managers and professionals in enterprises.

Research on intensity and patterns of managers and professionals tool usage can explain one aspect of the reasons for the state of tool usage in enterprises. The use of management tools is also influenced by tools drivers which include important personal, organizational and environmental organizational factors (Zheng et al. 2010; Lee et al. 2011; Potocan et al., 2013).

Our study targets correlates among three of the most frequently researched internal drivers: employees' personal characteristics, employees' role in the enterprise, and management tool usage in enterprises - more about drivers see in Zheng et al. (2010), Lee et al. (2011), and Potocan and Nedelko (2014, 2014a). The above mentioned theoretical and research findings about the drivers which influences on management tools usage suggest the following hypotheses:

H 3: Different drivers influence the use of management tools by managers and professionals in enterprises.

H3a: An employee's education level is significantly associated with their use of management tools.

H3b: An employee's work experiences are significantly associated with their use of management tools.

H3c: The size of the enterprise is significantly associated with the usage of management tools by employees.

\section{METHODOLOGY}

\section{Sample and Procedure}

Random sampling was done based on GVIN, a national directory that lists Slovenian enterprises. A total of 750 questionnaires were sent via post to the managers and professionals in selected enterprises in 2012. A maximum of two surveys were sent to managers and two to professionals in each enterprise. We received a total of 155 usable surveys for our analysis, resulting in $20.7 \%$ response rate.

The sample for this study included 61 managers at different management levels and 89 professionals from diverse enterprises in Slovenia. The sample included $48.4 \%$ males and 51.6\% females. The average age of respondents was 44.35 years; they had on average 20.49 years of work experience. In terms of education level, $61,1 \%$ had high school or university degrees, and $38.9 \%$ had earned master's degrees. In terms of enteprise size, $13.5 \%$ of enterprises had fewer than 10 employees, $18.7 \%$ had between 10 and 49 employees, $43.9 \%$ had between 50 and 249 employees, and $23.9 \%$ had more than 250 employees. 


\section{Measures}

To survey the employees' usage of management tools in enterprises, we developed a questionnaire. We combined lists of tools from Bain's survey (Rigby and Bilodeau 2009, 2011) and Potocan and Nedelko's survey (Potocan et al. 2012; Potocan and Nedelko, 2014; Potocan and Nedelko, 2014a).

The questionnaire comprised three parts. The first part included questions about using, knowing, satisfaction, and desire to use or familiarity with 25 management tools identified in the survey. The second part asked general questions about management tools. The third part asked for demographic data related to respondents and enterprises.

To measure the use of a single management tool, participants rated each tool included in the survey on a Likert-type scale ranging from "I know and use the tool" (1) to "I don't know and don't use the tool" (3). Some demographic variables were also measured using scales, like education level, organizational position, and enterprise size. For respondents' ages and work experience, participants provided specific numbers, while for department they selected the appropriate department.

Drivers of management tool use, employees' education level, years of work experience, and enterprise size were measured using a numerical scale.

\section{Research Design}

Based on Kolmogorov Smirnov normality tests, research practice, and suggestions from experts in this field (Ho 2006; Leech et al. 2008), our data did not markedly violate assumptions about normal distribution. In order to examine the frequency of professionals' and managers' use and patterns of management tool use, we used mean values, ranks, and independent sample t-tests. The results reported are for the 25 most frequently used management tools.

In terms of strength of the association between influential drivers and management tool use and variance explained, level of education, work experience, and enterprise size were included in the model for analysis.

Regarding Hypothesis 3, our main goal is to assess the influence of the most influential drivers on management tool use for professionals and managers in Slovenian enterprises. The use of management tools is thus predicted as a linear combination of three drivers. A path diagram is depicted in Figure 1.

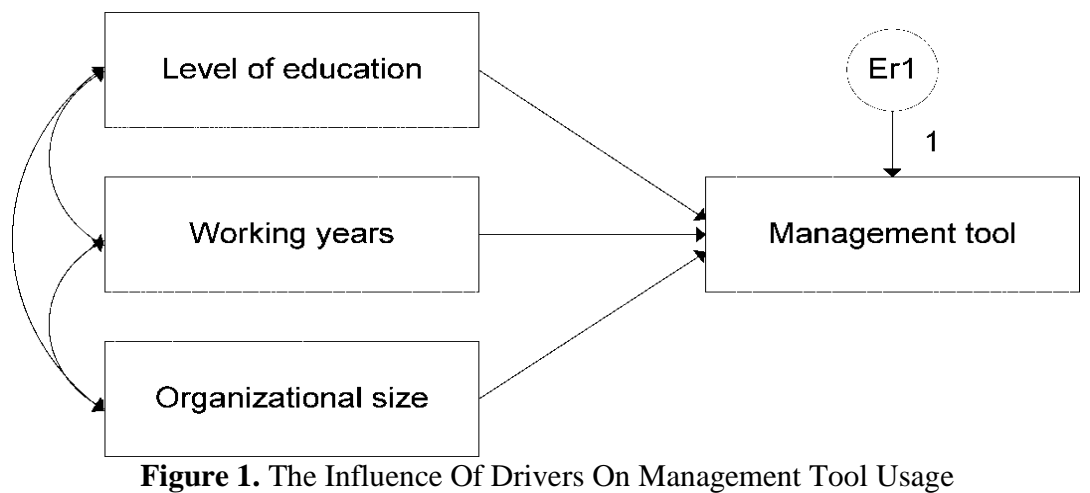

The proposed model was tested using AMOS, following the suggestions of Arbuckle (2007). We calculated estimates for the 25 most used management tools among professionals and managers. Fit statistics are not reported here, as suggested by Arbuckle (2007). We used independently observed variables - namely, the three drivers and use of management tool. 


\section{RESULTS}

Results about the frequency of managers' and professionals' management tool use in Slovenian enterprises are based on mean values for the 25 most used management tools, as self-reported by professionals and managers. The mean values and ranks for both groups and t-test results for each management tool's use are outlined in Table 2.

Table 2. Mean Values, Ranks, And T-Test Results For 25 Single Management Tools' Use By Professionals And Managers.

\begin{tabular}{|c|c|c|c|c|c|c|}
\hline \multirow{2}{*}{ Management Tools } & \multicolumn{6}{|c|}{ Groups of Employees } \\
\hline & Profess. & Rank - Profess. & Managers & Rank-Man. & $\mathbf{T}$ & Sig. \\
\hline Outsourcing (OUT) & 1.84 & 1. & 1.34 & 1. & 4.474 & 0.000 \\
\hline Benchmarking (BEN) & 1.97 & 2. & 1.42 & 2. & 5.230 & 0.000 \\
\hline Total Quality Management (TQM) & 2.08 & 6. & 1.52 & 3. & 5.375 & 0.000 \\
\hline Customer Relationship Management (CRM) & 2.18 & 8. & 1.67 & 4. & 4.234 & 0.000 \\
\hline Core Competencies (CC) & 2.07 & 5. & 1.69 & 5. & 2.798 & 0.006 \\
\hline Knowledge Management (KM) & 1.97 & 3. & 1.69 & 6. & 2.201 & 0.029 \\
\hline Strategic Planning (SP) & 1.97 & 4. & 1.70 & 7. & 2.552 & 0.012 \\
\hline Balance Scorecard (BSC) & 2.53 & 16. & 1.72 & 8. & 6.634 & 0.000 \\
\hline Mission and Vision Statements (MVS) & 2.25 & 9. & 1.79 & 9. & 3.539 & 0.001 \\
\hline Change management $(\mathrm{CM})$ & 2.18 & 7. & 1.87 & 10. & 2.526 & 0.013 \\
\hline Customer Segmentation (CS) & 2.36 & 11. & 1.90 & 11. & 3.913 & 0.000 \\
\hline Mergers and Acquisitions (MA) & 2.25 & 10. & 1.94 & 12. & 2.902 & 0.004 \\
\hline Loyalty Management (LM) & 2.39 & 13. & 2.04 & 13. & 2.979 & 0.003 \\
\hline Supply Chain Management (SCM) & 2.44 & 14. & 2.06 & 14. & 3.339 & 0.001 \\
\hline Scenario and Contingency Planning (SCP) & 2.54 & 17. & 2.07 & 15 . & 3.592 & 0.000 \\
\hline Strategic Alliances (SA) & 2.36 & 12. & 2.11 & 16. & 2.139 & 0.034 \\
\hline Six Sigma (SS) & 2.93 & 25. & 2.17 & 17. & 9.321 & 0.000 \\
\hline Social media programs (SMP) & 2.54 & 18. & 2.19 & 18. & 3.052 & 0.003 \\
\hline Collaborative Innovation (CI) & 2.56 & 19. & 2.24 & 19. & 2.833 & 0.005 \\
\hline Growth Strategies Tools (GST) & 2.51 & 15 . & 2.27 & 20. & 2.046 & 0.042 \\
\hline Lean Operations (LO) & 2.70 & 22. & 2.27 & 21. & 4.779 & 0.000 \\
\hline Offshoring (OS) & 2.70 & 23. & 2.46 & 22. & 2.625 & 0.010 \\
\hline Radio Frequency Identification (RID) & 2.89 & 24. & 2.47 & 23. & 4.815 & 0.000 \\
\hline Shared Service Centers (SSC) & 2.65 & 21. & 2.49 & 24. & 1.539 & 0.126 \\
\hline Consumer Ethnography (CE) & 2.57 & 20. & 2.51 & 25. & 0.638 & 0.525 \\
\hline
\end{tabular}

The rankings of management tool use show that outsourcing and benchmarking are the most used tools by managers and professionals. In terms of ranks, managers ranked some tools higher than professionals (e.g., TQM, CRM, BSC) but others lower than professionals (e.g., KM, SP, CM). The opposite is true from the viewpoint of professionals. Although, mean values for single management tools usage indicate that managers use considered 25 single management tools more often than professionals in Slovenian enterprises. These findings provide support for Hypothesis 1.

For research of differences in patterns of management tools use between managers and professionals, results of t-test for 25 tools (exception is consumer ethnography) support hypothesis 2 . Turning to the drivers of management tool use, we outlined results about the impact of employees' education level, employees' work experience, and enterprises' size on the usage of the top 10 management tools for both groups of employees. Standardized regression weights calculated in AMOS for management tool use by managers are outlined in Table 3 and for professionals in Table 4. 
Table 3. The Impact Of Key Drivers On Management Tools Usage By Managers

\begin{tabular}{lcccc}
\hline \multicolumn{1}{c}{ Management Tools } & \multicolumn{3}{c}{ Key Drivers } \\
\cline { 2 - 5 } & Education & Working Years & Enterprise Size & Variance Explained \\
\hline Outsourcing (1) & $-0.564^{* *}$ & 0.081 & 0.019 & $33.5 \%$ \\
Benchmarking (2) & $-0.593^{* *}$ & 0.130 & -0.107 & $47.0 \%$ \\
Total Quality Management (3) & $-0.705^{* *}$ & 0.090 & 0.079 & $48.5 \%$ \\
Customer Relationship Management (4) & -0.205 & 0.157 & -0.096 & $11.1 \%$ \\
Core Competencies (5) & $-0.557^{* *}$ & $0.167 *$ & -0.081 & $42.9 \%$ \\
Knowledge Management (6) & $-0.534^{* *}$ & $0.226^{*}$ & -0.053 & $41.7 \%$ \\
Strategic Planning (7) & $-0.422^{* *}$ & 0.107 & -0.030 & $21.9 \%$ \\
Balance Scorecard (8) & $-0.727^{* *}$ & -0.098 & 0.109 & $45.9 \%$ \\
Mission and Vision Statements (9) & $-0.413^{* *}$ & $0.221^{*}$ & -0.014 & $25.8 \%$ \\
Change management (10) & $-0.558^{* *}$ & $0.186^{*}$ & -0.064 & $42.8 \%$ \\
Mergers and Acquisitions (12) & $-.0624^{* *}$ & 0.024 & 0.144 & $33.6 \%$ \\
\hline
\end{tabular}

$* \mathrm{p}<0.05 ; * * \mathrm{p}<0.001$

Table 4. The Impact Of Key Drivers On Management Tools Usage By Professionals

\begin{tabular}{lcccc}
\hline \multicolumn{1}{c}{ Management Tools } & \multicolumn{3}{c}{ Key Drivers } \\
\cline { 2 - 5 } \multicolumn{1}{c}{ Education } & Working Years & Enterprise Size & Variance Explained \\
\hline Outsourcing (1) & -0.001 & 0.097 & $0.369^{*}$ & $14.9 \%$ \\
Benchmarking (2) & -0.087 & 0.159 & $0.284 *$ & $12.5 \%$ \\
Total Quality Management (6) & 0.163 & 0.079 & 0.029 & $2.9 \%$ \\
Customer Relationship Management (8) & 0.045 & 0.086 & 0.008 & $0.8 \%$ \\
Core Competencies (5) & 0.057 & 0.031 & -0.071 & $0.9 \%$ \\
Knowledge Management (3) & 0.002 & 0.084 & -0.127 & $2.2 \%$ \\
Strategic Planning (4) & 0.098 & 0.049 & 0.037 & $1.2 \%$ \\
Balance Scorecard (16) & 0.133 & 0.128 & 0.227 & $7.9 \%$ \\
Mission and Vision Statements (9) & 0.231 & 0.120 & 0.227 & $10.7 \%$ \\
Change management (7) & 0.118 & 0.074 & 0.157 & $4.1 \%$ \\
Mergers and Acquisitions (10) & 0.147 & 0.175 & 0.054 & $4.6 \%$ \\
\hline
\end{tabular}

$* \mathrm{p}<0.05 ; * * \mathrm{p}<0.001 ; \mathrm{ns}-$ not significant

Employees' level of education was significantly associated with use of the majority of the top 10 management tools used by managers, with the exception of customer relationship management. Thus, we can conclude that a higher education level is associated with a higher use of single management tools by managers. On the other hand, education does not significantly influence professionals' use of any of the top 10 tools used. Results for nine (out of ten) tools used by managers, support Hypothesis 3a. Results for professionals do not support Hypothesis 3a.

Employees' work experience was found to be significantly associated with use of four management tools by managers, meaning that managers with less work experience use management tools more often. Results for usage of four management tools by managers support hypotheses $3 \mathrm{~b}$. Work experience does not significantly influence on professionals' use of considered management tools and research results not support hypothesis $3 \mathrm{~b}$ for professionals.

Enterprise size is not a significant predictor of managers' management tool use, but it significantly influences professionals' use of two tools. These results do not support Hypothesis 3c for managers. On the contrary, professionals in smaller enterprises are more inclined to use outsourcing and benchmarking than those in larger ones. The results for outsourcing and benchmarking support Hypothesis $3 \mathrm{c}$ for professionals.

\section{DISCUSSION}

The international comparison of most used management tools between Slovenian enterprises and enterprises from other considered areas shows differences in tools usage. For example, a comparison of patterns emerging from Rigby and Bilodeau's $(2009,2011)$ studies about the 25 most frequently used tools worldwide and from our study shows differences in patterns of tools usage for considered tools in compared areas. A more comprehensive research of international differences in management tools' usage exceeds limitation of our research. 
Our study also revealed different frequencies and resulting patterns of managers' and professionals' management tool usage in Slovenian enterprises. These results matched the general cognition from previous studies that managers use tools more often than other groups of employees. For example, Ferratt et al. (2005) reported about the differences in the frequency of IT tool use between managers and professionals in organizations.

In our research we aimed our intention on examination of key drivers for 10 top most used tools by managers and professionals in considered enterprise. On the base from cognitions of previous studies we included in our research three drivers, which importantly determine tools use - i.e. education, work experiences, and enterprise size (Armstrong, 2006; Lee et al. 2011; Potocan and Nedelko, 2014a).

Our cognitions about influences of education reflect same findings as previous studies, where authors presented positive correlations between level of education and use of individual or several management tools for employees. Thus, Camelo-Ordaz et al. (2012) reported about existence of positive correlates between the education of employees and use of innovation tools in small enterprises, and Jarzabkowski et al. (2013) reported that educational characteristics of employees drive the adoption of strategic management tools.

Research also reveals that managers' usage of all management tools and professionals' use of the majority of management tools do not depend upon the size of the enterprises. It seems that organizational size does not play a crucial role in managers' usage of tool, although employees in smaller organizations tend to use outsourcing and benchmarking more than those in larger organizations (Armstong, 2006; Mullins 2010; Jereb et al., 2013).

On the other hand, previous studies have presented positive correlates between enterprises' size and employees' usage of single management tools. Thus, Zheng et al. (2010) reported that organization size through specific organizational structure influences usage of knowledge management, and Vaccaro et al. (2012) found that correlates exist between managers' leadership styles in small and large organizations and level of employees' usage of innovation tools. Another example of differences from previous studies outlined our result about the weak impact of work experience on managers' tools' use and their insignificant impact on professionals' usage of tools (Ralston et al., 2011; Jerman and Zavrsnik, 2012; Hauptman et al., 2014; Potocan and Nedelko, 2014a).

\section{CONCLUSIONS}

Our study examined frequency and patterns of management tools use, characteristics of managers' and professionals' tool usage in enterprises, and key drivers - i.e., education, work experience, and enterprise size, which influence the usage of tools in considered enterprises.

Results of international comparison of top ten most used management tools shows that the extent of the usage of the majority of management tools in Slovenian enterprises differs from their usage in enterprises between compared international areas. Study results also introduce differences in frequencies and patterns of 25 most used management tools among managers and professionals in sample of Slovenian enterprises. Mean values for single management tools usage indicate that manager's use considered 25 single management tools more often than professionals. Results of t-test for single tools (exception is consumer ethnography) reveal differences in patters of tools use. Results additionally show how considered internal tools drivers influence on management tools usage among managers and professionals in enterprises. For managers is evident that education dominantly influence on their use of management tools, work experiences had only a minor impact, while organizational size does not significantly influence. For professionals, we found that enterprise size significantly influence on usage of two tools, while the impact of education and working year is not significant. Based on a plethora of possible other factors, three factors included in our analysis, satisfactory explain the variance of considered ten tools. With research results we offer some explanation about the association between tools drivers and rank and adjacent hierarchy of tools usage among managers and professionals in considered enterprises.

The contribution and potential utility of this research are theoretical and practical. Results of our study contributes to the previous finding with new theoretical cognitions about comparison, selection and utilization of tools in enterprise's working and especially about disseminate knowledge for utilization of management tools usage, especially in production practices. Established results offer several theoretical implementations like more 
comprehensive understanding, theoretical framework for broader examination, and disseminate knowledge for tools use in organizational practice. Results also offer practical implications, as disseminate knowledge for improving production practices they can serve as a basis for future researches about comparison of tool usage.

Despite all the possibilities offered by the proposed research, this study still has some limitations that stand in the way for future researches. In terms of the reliability of the data, the pattern of results supports our interpretation of the causal relationships (Podsakoff et al., 2003). Another limitation of our study is measurement of management tool use only from the perspectives of two unified groups of employees-namely, managers and professionals. The contents limitation is related to excluding the possible impact of different business conditions on management tools usage.

\section{AUTHOR INFORMATION}

Sonja Treven, Ph.D. (in Business) is a Full Professor of Human Resource Management at the Faculty of Economics and Business (FEB), University of Maribor (Slovenia). She is head of Department of Management and Organization and head of Institute for management research in FEB. She takes part in different international scientific conferences and has conducted a number of study visits abroad. She has published over 300 texts, including 8 books, edited proceedings and textbooks. Dr. Treven has published over eighty articles in peer reviewed scholarly journals including but not limited to kybernetes, cybernetics and systems, and social indicators research. Prof. Dr. Sonja Treven, Department of Management and Organization, Faculty of Economics and Business, University of Maribor, Razlagova 14, Maribor, Slovenia. E-mail: sonja.treven@uni-mb.si

\section{REFERENCES}

Arbuckle, J.L. (2007). Amos 16.0 User's Guide. Chicago: Amos Development Corporation. Armstrong, M. (2006). A Handbook of Management Techniques. London: Kogan Page.

Camelo-Ordaz, C., Fernandez-Alles, M., Ruiz-Navarro, J., \& Sousa-Ginel, E. (2012). The Intrapreneur and Innovation in Creative Firms. International Small Business Journal, 30(5), 513-535.

Choudhary, A.K., Harding, J., Camarinha-Matos, L.M., Koh, S.C.L., \& Tiwari, M.K. (2013). Knowledge management and supporting tools for collaborative networks. International Journal of Production Research, 51 (7), 1953-1957.

Dabic, M., Potocan, V., Nedelko, Z., \& Morgan, T. (2013). Exploring the use of 25 leading business practices in transitioning market supply chains. International journal of physical distribution \& logistics management, 43(10), 833-851.

Ferratt, W., Agarwal, R., Brown, V., \& Moore, E. (2005). IT human resource management configuration and IT turnover: Theoretical synthesis and empirical analysis. Information systems research, 16(3), 237-255.

Hauptman, L., Horvat, M., \& Korez-Vide, R. (2014). Improving tax administration's services as a factor of tax compliance: The case of tax audit. Lex localis, 12(3), 481-501.

Ho, R. (2006). Handbook of Univariate and Multivariate Data Analysis and Interpretation with SPSS. Boca Raton: Chapman \& Hall.

Jarzabkowski, P., Giulietti, M., Oliveira, B., \& Ammoo, N. (2013). We Don't Need No Education"—Or Do We? Management Education and Alumni Adoption of Strategy Tools. Journal of Management Inquiry, 22(1), 424.

Jereb, B., Ivanusa, T., \& Rosi, B. (2013). Systemic thinking and requisite holism in mastering logistics risks: The model for identifying risks in organizations and supply chain. Amfiteatru economic, 15(33), 56-73.

Jerman, D., \& Zavrsnik, B. (2012). The model of marketing communications effectiveness: Empirical evidence from Slovenian business-to-business practice. Journal of business economics and management, 13 (4), 705-723.

Kannan, V., \& Tan, K. (2005). Just in time, Total quality management, and Supply chain management: Understanding their linkages and impact on business performance. OMEGA: The International Journal of Management Science, 33(2), 153-162.

Kumar, M., Antony, J., \& Tiwari, M.K. (2011). Six Sigma implementation Framework for SMEs: A roadmap to manage and sustain the change. International Journal of Production Research, 49 (18), pp. 5449-5467.

Lee, L., Wong, P.K., Foo, M.D., \& Leung, A. (2011). Entrepreneurial intentions: The influence of organizational and individual factors. Journal of Business Venturing, 26(1), 124-136. 
Leech, N.L., Barrett, K.C., \& Morgan, G.A. (2008). SPSS for Intermediate Statistics. New York: Taylor \& Francis. Morgan, J., \& Wang, R. (2010). Tournaments for Ideas. California Management Review, 52(2), 77-97.

Mullins, L. (2010). Management and Organisational Behaviour. New York: Prentice Hall.

O'Hare, J., Dekoninck, E., McMahon, C., \& Turnbull, A. (2010). Adapting innovation tools to the eco-innovation requirements of industry: Case study results. International Journal of Design Engineering, 3(2), 172-194.

Podsakoff, P., MacKenzie, S., Lee, J., \& Podsakoff, N. (2003). Common method biases in behavioral research: A critical Review of the literature and recommended remedies. Journal of Applied Psychology, 88(5), 879903.

Potocan, V., \& Nedelko, Z. (2014). Management innovativeness: A case of Slovenian small- and medium enterprises. Transformations in business \& economics, 13(1), 41-59.

Potocan, V., \& Nedelko, Z. (2014a). A New Socio-economic Order: Evidence About Employees' Values' Influence on Corporate Social Responsibility. Syst. Res., doi: 10.1002/sres.2264.

Potocan, V., Nedelko, Z., \& Mulej, M. (2012). Influence of organizational factors on management tools usage in Slovenian organizations. Engineering Economics, 23(3), 291-300.

Potocan, V., Mulej, M., \& Nedelko, Z. (2013). The influence of employees' ethical behavior on enterprises' social responsibility. Systemic practice and action research, 26(6), 497-511.

Ralston, D., Egri, C., Reynaud E., Srinivasan, N., et al. (2011). A Twenty-First Century Assessment of Values across the Global Workforce. Journal of Business Ethics, 104(1), 1-31.

Ralston, D., Egri, C., Furrer, O., Mockaitis, A. et al. (2014). Societal-level versus individual-level predictions of ethical behavior: A 48-society study of collectivism and individualism. Journal of business ethics, 122(2), 283-306.

Regazzoni, D., Rizzi, C., \& Nani, R. (2011). A TRIZ-based approach to manage innovation and intellectual property. International Journal of Technology Management, 55(3/4), 274-285.

Rigby, D., (2001). Situational strategies: A management tool for turbulent times. Strategy \& Leadership, 29(6), 812.

Rigby, D., \& Bilodeau, B. (Eds) (2009). Management tools and trends 2009. Retrieved February 13, 2014, from http://www.bain.com

Rigby, D., \& Bilodeau, B. (Eds) (2011). Management tools and trends 2011. Retrieved February 13, 2014, from http://www.bain.com

Thun, J. (2010). Angles of integration: An empirical analysis of the alignment of internet-based information technology and global supply chain integration. Journal of Supply Chain Management, 46(2), 30-44.

Vaccaro, I., Jansen, J., Van Den Bosch, F., \& Volberda, H. (2012). Management Innovation and Leadership: The Moderating Role of Organizational Size. Journal of Management Studies, 49(1), 28-51.

Zheng, W., Yang, B. Y., \& McLean, G. (2010). Linking organizational culture, structure, strategy, and organizational effectiveness: Mediating role of knowledge management. Journal of Business Research, 63(7), 763-771. 


\section{NOTES}

